\title{
F-Box-Like/WD Repeat-Containing Protein TBL1XR1
}

National Cancer Institute

\section{Source}

National Cancer Institute. F-Box-Like/WD Repeat-Containing Protein TBL1XR1. NCI

Thesaurus. Code C80118.

F-box-like/WD repeat-containing protein TBL1XR1 (514 aa, $\sim 56 \mathrm{kDa}$ ) is encoded by the human TBL1XR1 gene. This protein is involved in the modulation of transcription. 